\title{
Optic glioma of childhood: clinical, histopathological, and histochemical observations
}

\author{
SEVGÜL BİLGİÇ, AYKUT ERBENGİ, BEHÇET TINAZTEPE, \\ AND BEHSAN ÖNOL \\ From the 'Departments of Ophthalmology, Neurosurgery, and Pathology, Hacettepe University, Ankara, \\ Turkey
}

SUMMARY This report documents the long-term clinical and histopathological behaviour of eight intraorbital and 16 intracranial optic nerve gliomas and relates the therapeutic data to the prognosis for both visual acuity and survival. The mean age at onset of symptoms was 8.6 years and at the diagnosis 10.9 years. It is generally held that proptosis is mild in intraorbital glioma, but we encountered marked proptosis ranging from 7 to $12 \mathrm{~mm}$ in six of the eight intraorbital gliomas, which contained abundant Alcian-blue-positive mucoid material. Of the patients with intracranial optic nerve gliomas $37 \cdot 5 \%$ survived for a mean of eight years after treatment with radiotherapy or surgery combined with radiotherapy. At follow-up ranging from five months to 11 years only one of the six patients with intracranial gliomas had full visual acuity. Our observations emphasise that, although optic nerve gliomas are benign hamartomas, the prognosis for visual acuity and survival is unfavourable in cases which are diagnosed and treated late. Histopathological and histochemical observations suggest that increase in the amount of mucoid material may contribute to rapid enlargement of intraorbital and intracranial optic gliomas.

Since the first description of optic glioma by Scarpa in 1816 much has been written on their natural course and treatment.' Most optic gliomas are low-grade pilocytic astrocytomas, and excision of the tumour results in a benign course. Malignant optic nerve gliomas are rare. ${ }^{2}$ Death from intracranial optic glioma may be from mechanical pressure on vital structures, mainly owing to enlargement of the tumour. ${ }^{3}$ Anderson and Spencer ${ }^{3}$ emphasised the accumulation of mucinous material within the tumour as an important cause of its enlargement together with proliferation of neoplastic astrocytes and a reactive proliferation of arachnoidal tissue.

The present study reports the clinical findings and the effect of treatment on visual acuity and survival in children with histologically confirmed glioma of the optic nerve or chiasm. In addition, the effect of collateral meningeal hyperplasia and accumulation of mucoid material was studied histopathologically and histochemically as a possible mechanism for

Correspondence to Professor S Bilgiç, Hacettepe Üniversitesi, Hastaneleri, Turkey. enlargement of the tumour causing rapid exophthalmos or progressive deterioration of the patients' health.

\section{Material and methods}

The hospital records of 24 patients with histopathologically confirmed optic gliomas seen in the Departments of Ophthalmology and Neurosurgery at Hacettepe University from 1968 through 1982 were reviewed. Eight patients with orbital and 16 patients with intracranial optic gliomas were examined with regard to age, sex, and mode of onset of symptoms and signs. The surviving patients were followed up in an attempt to correlate the therapy with visual acuity and survival. The follow-up periods ranged from 5 months to 11 years, mean 8 years.

Sections of tumour blocks were prepared and histological verification of tumour cells was carried out in accordance with WHO criteria. ${ }^{+}$All the sections were stained with haematoxylin-eosin, alcian blue, and mucicarmine for light microscopy. 


\section{Results}

Histopathological examination revealed in all cases that the tumour cells were mostly piloid astrocytes. In almost all these tumours microcystoid spaces contained different amounts of mucopolysaccharides staining positive with alcian blue (Fig. 1). In four of the six cases of prominent exophthalmos with intraorbital glioma and in two of the cases of intracranial optic glioma ( 9 and 15 months old) histopathological evidence of mucosubstance to a greater degree than others was found by the alcian blue technique. Mucicarmine staining was negative in all tumours. The histopathological study showed collateral hyperplasia surrounding the optic nerve in two cases of intraorbital tumour with clinical evidence of severe exophthalmos (Fig. 2).

Frequency. During a 14-year period we found 24 cases of optic glioma of which eight were confined to the orbit. These tumours constituted $13.7 \%$ of the histopathologically diagnosed intraorbital tumours and were the most common orbital tumour during that period.

Localisation. In 16 cases the optic glioma was located intracranially. In 12 of these it was only chiasmal, and six patients had expansion of both optic nerves as well as involvement of the chiasm (Table 1). In five cases the third ventricle was involved and in one case the sinus cavernosus. In eight cases the tumour was located in the orbital part of the optic nerve alone.

Sex. Of the 24 patients 13 were male and 11 female.

Age. The range was 9 months to 53 years. The oldest patient had had relevant clinical symptoms 20 years before admission to the hospital. Table 2 gives the age onset of symptoms and the age at which the diagnosis was made in 24 patients with optic glioma.

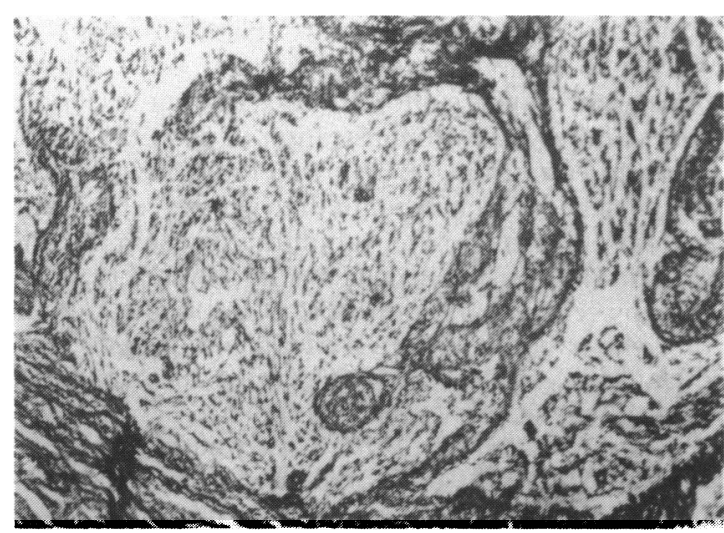

Fig. 1 Mucinous material in cystoid spaces in optic nerve glioma. (Haematoxylin-eosin).

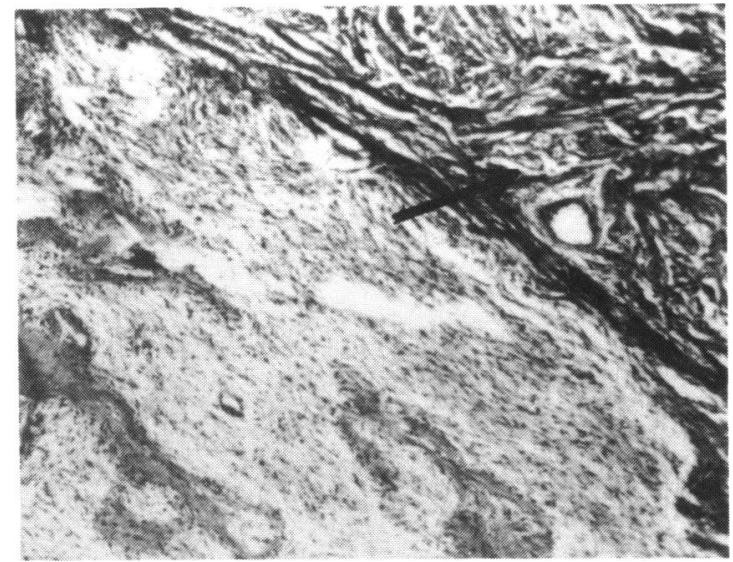

Fig. 2 Collateral hyperplasia surrounding the optic nerve glioma (arrow). (Haematoxylin-eosin).

The mean age at onset of symptoms was 8.6 years and at diagnosis 10.9 years. If the 53 -year-old patient is excluded, the mean age at onset of symptoms would fall to $7 \cdot 6$ years.

The peak incidence of onset of the earliest symptoms was at ages $1-7$ years, while the peak incidence at diagnosis at $7-15$ years.

Symptom and signs. Table 3 summarises the symptoms and signs of 24 patients grouped according to the initial symptoms and signs noted at first admission to hospital and during follow-up examinations. The first two most commonly encountered initial ocular symptoms in both groups were diminished visual acuity and exophthalmos. Diminished monocular visual acuity was present in eight patients with tumour confined to the orbit and ranged between absolute and 0.3 at the onset of the disease. The visual acuity of 16 patients with intracranial optic

Table 1 Localisation of optic nerve gliomas

\begin{tabular}{lr} 
Intraorbital glioma & 8 \\
Intracranial glioma & 16 \\
Chiasmal & 12 \\
Chiasmal+both optic nerves involved & 6 \\
Third ventricle involved & 5 \\
Sinus cavernosus involved & 1 \\
\hline
\end{tabular}

Table 2 Age of 24 patients with optic glioma at onset of symptoms and diagnosis

\begin{tabular}{lcr}
\hline Age & \multicolumn{2}{c}{ Number of patients } \\
\cline { 2 - 3 } & Onset of symptoms & Diagnosis \\
\hline Under 1 & $2(8 \%)$ & $2(8 \%)$ \\
$1-$ & $15(62 \%)$ & $9(37 \%)$ \\
$7-15$ & $7(29 \%)$ & $13(54 \%)$ \\
\hline
\end{tabular}


Table 3 Symptoms and signs in 24 patients with optic glioma

\begin{tabular}{|c|c|c|c|c|}
\hline \multirow[b]{2}{*}{ Ocular } & \multicolumn{2}{|c|}{$\begin{array}{l}\text { Initial symptoms } \\
\text { and signs on } \\
\text { admission }\end{array}$} & \multicolumn{2}{|c|}{$\begin{array}{l}\text { Symptoms and signs } \\
\text { at follow-up }\end{array}$} \\
\hline & Orbital & Intracranial & Orbital & Intracranial \\
\hline \multicolumn{5}{|l|}{ Dimished visual acuity } \\
\hline Monocular & 8 & 6 & 8 & - \\
\hline Binocular & - & 10 & - & 5 \\
\hline Exophthalmos & 8 & 3 & 8 & 3 \\
\hline Strabismus & 5 & 4 & 7 & 4 \\
\hline Nystagmus & - & 3 & - & 6 \\
\hline \multicolumn{5}{|l|}{ Optic disc changes } \\
\hline Papilloedema & & & - & - \\
\hline Unilateral & 1 & - & & \\
\hline Bilateral & - & 2 & & \\
\hline \multicolumn{5}{|l|}{ Optic atrophy } \\
\hline Unilateral & 6 & 6 & 8 & 3 \\
\hline Bilateral & - & 10 & - & 4 \\
\hline Visual field defect & - & - & - & 6 \\
\hline \multicolumn{5}{|l|}{ Others } \\
\hline $\begin{array}{l}\text { Increased intracranial } \\
\text { pressure }\end{array}$ & - & 8 & - & 12 \\
\hline Hydrocephalus & - & 8 & - & - \\
\hline Multiple café au lait spots & 56 & - & 6 & - \\
\hline Paresis & - & 1 & - & 5 \\
\hline Acromegaly & - & - & - & 1 \\
\hline Precocious puberty & - & 1 & - & 1 \\
\hline
\end{tabular}

glioma was usually extremely low owing to bilateral optic atrophy at first admission to the hospital.

All patients with intraorbital optic gliomas had exophthalmos. In six it was severe, ranging between 7 and $12 \mathrm{~mm}$ measured by Hertel exophthalmometer (Fig. 3).

The optic disc changes were usualy of the optic atrophy type rather than papilloedema in whether intraorbital or intracranial tumours were the feature. Multiple café au lait spots were evident in six patients $(25 \%)$. A 20 -year-old woman with optic glioma also had an acoustic neurinoma, and a neurifibroma at the cerebellopontine angle as well as an intradural neurinoma extirpated at the level of $L_{1}-L_{4}$.

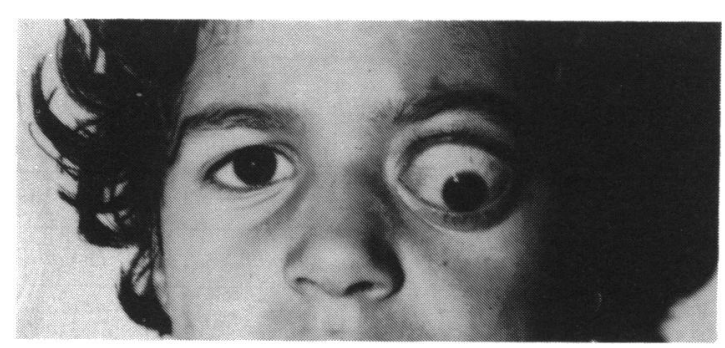

Fig. 3 A 6-year-old girl with an orbital glioma presenting with $12 \mathrm{~mm}$ exophthalmos in her left eye.
Table 4 Radiological findings in 24 patients with optic glioma

\begin{tabular}{lll}
\hline & $\begin{array}{l}\text { Orbital } \\
\text { optic glioma } \\
(n=8)\end{array}$ & $\begin{array}{l}\text { Intracranial } \\
\text { optic glioma } \\
(n=16)\end{array}$ \\
\hline Enlargement of optic foramen & $3(37 \cdot 5 \%)$ & $12(75 \%)$ \\
Enlargement of orbit & $1(12 \cdot 5 \%)$ & - \\
Sella turcica & - & $3(18 \cdot 7 \%)$ \\
$\quad$ Enlarged pituitary fossa & - & $6(37 \cdot 5 \%)$ \\
$\quad$ Deformed dorsum sella & - & $4(25 \%)$ \\
$\quad$ Calcification & - & $10(62 \cdot 5 \%)$ \\
Separation of intracranial sutures & - & \\
\hline
\end{tabular}

RADIOLOGICAL FINDINGS

Table 4 indicates the radiological findings in the 24 cases. In 3 cases $(37.5 \%)$ of intraorbital and in 12 $(75 \%)$ of intracranial tumours an enlarged optic foramen with regular borders was noted (Fig. 4A,B). These three patients with enlarged optic foramen underwent both lateral and transfrontal orbitotomy and did not show any evidence of intracranial extension of the tumour.

Two intracranial cases with chiasmal involvement showed bilateral enlargement of the optic foramen. A 20-year-old woman with complaints of six years' duration showed enlargement of orbital bones radiologically. Thirteen out of 16 cases of intracranial optic glioma had various radiological defects of the sella turcica (Table 4).

RELATION OF THERAPY TO VISION AND SURVIVAL

The types of treatment given in cases of orbital and intracranial optic glioma, and their relationship with tumour localisation and the patients' survival status, are summarised in Table 5. Five out of the total eight patients with intraorbital optic glioma had a modified Krönlein operation, and three other patients had a Krönlein operation and transfrontal orbitotomy.

The 16 patients with intracranial optic glioma underwent biopsy, subtotal or total tumour resection, and postoperative administration of 5500 rad radiation and carmustine (BCNU) therapy. Seven of the patients died within one month to seven years. These patients had extensive tumoural invasion of the chiasm and third ventricle. As an adjunct to other therapy ventricular shunts were performed in five out of eight patients with hydrocephalus diagnosed by pneumoencephalography. Three of these patients were still living at the time of study.

The survival status of three other patients was not known. Three out of six patients with intracranial optic glioma who underwent total or subtotal excision of tumour with postoperative radiation therapy were still living after 11 years. A mean duration of eight 


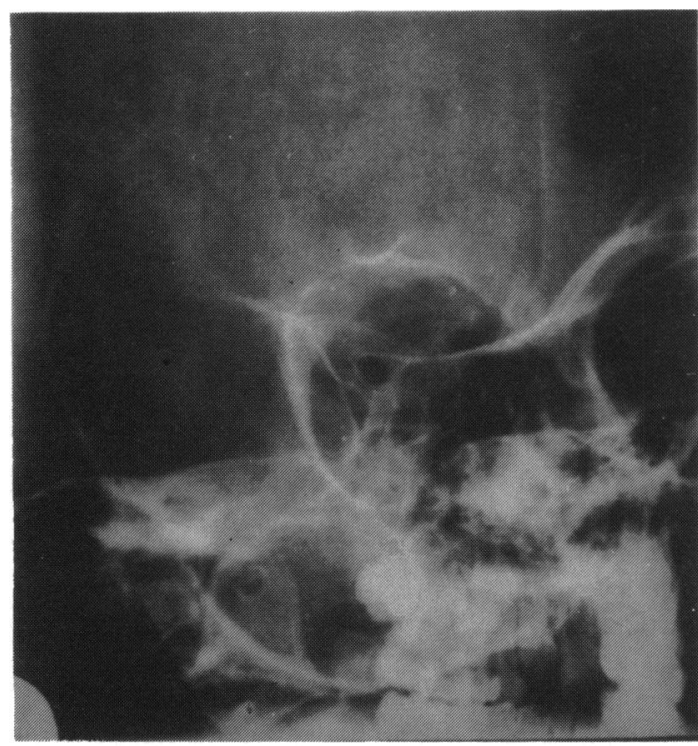

Fig. 4A

Fig 4 A:Orbital and intracranial optic nerve glioma in a 7-year-old girl. The normal left optic nerve canal. B: The right optic canal is enlarged to $8.5 \mathrm{~mm}$ diameter (arrow).

years' follow-up on our series of 16 patients showed $37.5 \%$ with intracranial optic glioma were alive.

The effect of therapy on visual acuity in 14 patients with optic glioma is given in Table 6 . The visual acuity of patients with intracranial optic nerve glioma remained stable in low degrees. Only one patient had full vision after biopsy followed by radiation therapy.

\section{Discussion}

Optic glioma has been considered rare..$^{15-4}$ In our series optic nerve glioma constituted $13 \cdot 7 \%$ of all orbital tumours, thus being the commonest intraorbital tumour. Most observers have reported that optic glioma is commoner in the chiasm than the optic nerves. ${ }^{51011}$ The ratio of intracranial to intraorbital optic gliomas in our series was 2 . The involvement of the chiasm in 12 cases of the intracranial optic gliomas and of the third ventricle in 5 supports the idea that they may be expansile, though they are accepted as being benign hamartomatous self-limiting tumours.

Lloyd ' and Yanoff and Fine ${ }^{12}$ reported a preponderance of optic glioma in girls, contrary to our observations of an equal sex distribution, which has been also reported by Henderson. ${ }^{5}$

There is general agreement on the congenital origin of this tumour owing to its appearing in infants and preschool children."11.3 Our study tends to

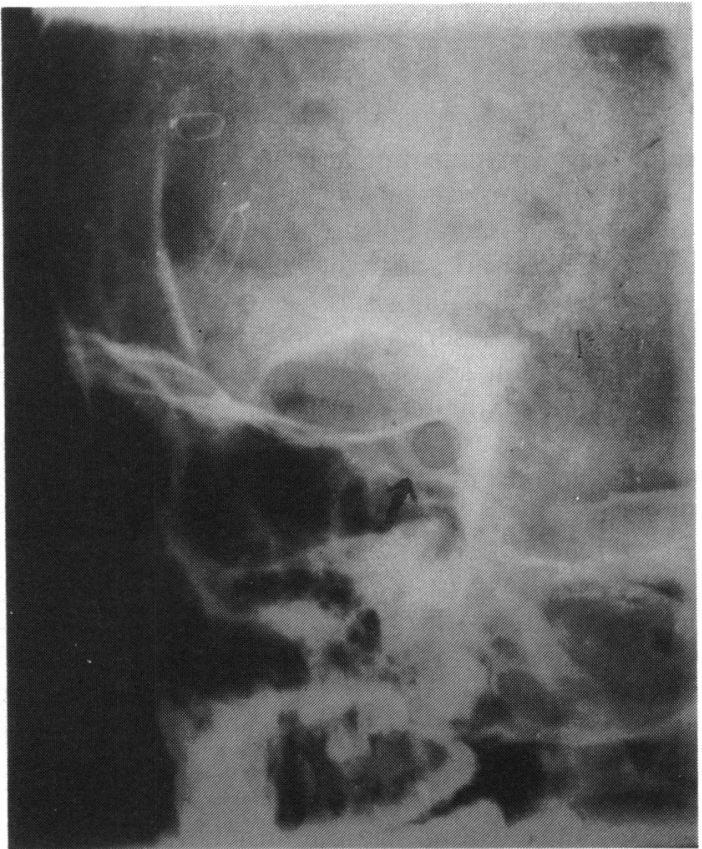

Fig. 4B

Table 5 Relation of therapy with tumour location and survival in 24 optic glioma cases

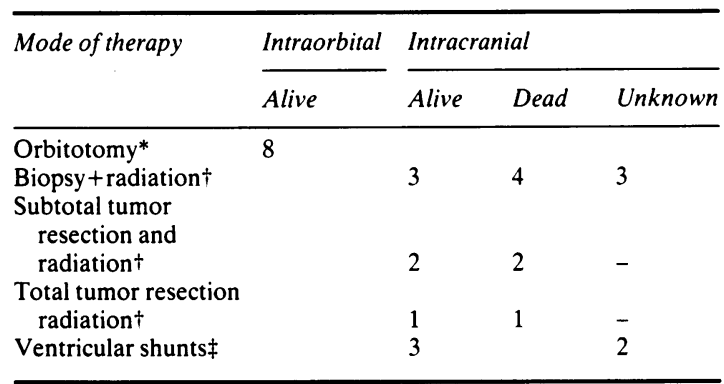

*Five patients underwent lateral orbitotomy (modified Krönlein). three patients underwent lateral and transfrontal orbitotomy.

†All patients received average 5500 rad radiotherapy and carmustine therapy.

$\ddagger$ Ventricular shunts were performed in five cases in addition to other therapy.

Table 6 Effect of therapy on prognosis for visual acuity in total of 14 survived optic glioma cases

\begin{tabular}{lllll}
\hline Localisation & $\begin{array}{c}\text { No. of } \\
\text { patients }\end{array}$ & \multicolumn{3}{l}{ Visual acuity } \\
\cline { 3 - 5 } & & Decreased & Stable & Increased \\
\hline Orbital & 8 & 8 (absolute) & - & - \\
Intracranial & 6 & - & 6 & - \\
Total & 14 & 8 & 6 & - \\
\hline
\end{tabular}


support this view, because approximately $71 \%$ of patients had symptoms and signs before 7 years of age.

Although exophthalmos is accepted as a favourable prognostic sign, indicating intraorbital localisation of the tumour, exophthalmos was present in $18.7 \%$ of our cases of intracranial tumours as compared with $20 \%$ of Chutorian and colleagues' ${ }^{\prime \prime}$ cases. A mild degree of exophthalmos rarely exceeding $3 \mathrm{~mm}$ was reported in their series in contrast with our intraorbital cases, in six of which we observed severe degrees of exophthalmos varying from 7 to $12 \mathrm{~mm}$. In most of our cases of intraorbital gliomas the eyes were displaced inferonasally and inferotemporally, though Reese $^{6}$ described straightforward displacement in mild degrees of exophthalmos.

In four of the six cases of prominent exophthalmos the histopathological examination revealed large cystoid spaces filled with alcian-blue-positive mucoid material, a finding that supports the idea of rapid enlargement of the tumour due to abundant accumulation of mucosubstance, as previously shown by Anderson and Spencer. ${ }^{3}$ Enormous amounts of mucosubstance within the tumour might account for a sudden increase in degree of exophthalmos in orbital gliomas as well as causing important functional disturbances in intracranial optic gliomas.

In the literature optic gliomas arising within the orbit adjacent to the eye globe are said to produce papilloedema in contrast to the optic atrophy associated with tumours located distal to the eye or intracranially. ${ }^{710}$ We failed to find any relationship between papilloedema and atrophy in accordance with tumour localisation in our study.

The relation between optic glioma and von Recklinghausen's disease has long been recognised. The incidence ranges from $10 \%$ to $30 \% .^{5}$ Lloyd $^{7}$ found $40 \%$ of patients with optic glioma had stigmata of neurofibromatosis. We reported café au lait spots in six patients $(25 \%)$ with optic glioma, which is in accordance with published reports. A 20-year-old girl who was found to have histopathologically confirmed intracranial neurofibroma, acoustic neurinoma, and neurinoma of the lumbar region besides optic glioma is a good example of the association of optic gliomas with other tumours as noted by Walsh and Hoyt."

We have observed a gratifying success in approaching progressive intraorbital gliomas by the Krönlein operation described by Berke..$^{14}$ No patient in our series had recurrence of the orbital tumour, which is in accordance with Tym's ${ }^{15}$ and Spencer's' ${ }^{16}$ observations. Marejawa and colleagues ${ }^{17}$ reported recurrences of incompletely excised intraorbital and intracranial optic gliomas.

The best treatment of intracranial optic gliomas is still controversial-whether surgery, radiotherapy, or both. ${ }^{7101819}$ We could not find any correlation with the mode of therapy and its effect on survival and visual acuity because of the small numbers of patients receiving different types of treatment.

A mean duration of eight years' follow-up in our own series showed a low survival rate of $37.5 \%$ in cases of intracranial optic glioma. Rush and colleagues $^{20}$ reported that $85 \%$ of patients with gliomas of the optic nerve or chiasm had survived a mean duration of 17 years, while $44 \%$ of the patients with chiasmal optic gliomas survived a mean duration of 19 years.

In conclusion, a follow-up study with a mean duration of eight years in our own series of 24 patients demonstrated that, though optic gliomas are accepted as benign hamartomatous tumours, they can have an aggressive course, affecting the chiasm and third ventricle and leading to a fatal outcome. The low survival rate as of $37.5 \%$ in our series might be taken as a good evidence of the aggressive nature of these tumours. As there are so many conflicting views on the therapy of optic nerve gliomas, the surgeon should evaluate each case individually. Patients should be examined at regular intervals, with special attention to visual acuity and neurological signs so that the best time and mode of therapy can be selected.

\section{References}

1 Eggers $\mathrm{H}$, Jakobiec FA, Jones IS. Optic nerve gliomas. In: Duane TD, ed. Clinical ophthalmology. Philadelphia: Harper and Row, 1985: Chapter 42: 1-17.

2 Hamilton AM, Garner, Tripathi RC, Sanders MD. Malignant optic nerve glioma. Br J Ophthalmol 1973; 57: 253-64.

3 Anderson DR, Spencer WH. Ultrastructural and histochemical observations of optic nerve gliomas. Arch Ophthalmol 1970; 83: 324-35.

4 Zülch KJ. Histopathologic typing of tumours of the central nervous system. Geneva: World Health Organisation, 1979: 19-24.

5 Henderson JW. Orbital tumours. Philadelphia: Saunders, 1973: Chapter 17: 495-526.

6 Reese AB. Tumours of the eye. 2nd ed. New York: Hoeber, 1963: 162-79.

7 Loyd LA. Gliomas of the optic nerve and chiasm in childhood. Trans Am Ophthalmol Soc 1973; 71: 488-535.

8 Gombi R, Hullay J. Diagnosis and treatment of the optic glioma. Acta Neurochirwien Suppl 1979; 28: 405-8.

9 MacCarty CS, Boyd AS, Childs DS. Tumors of the optic nerve and optic chiasm. J Neurosurg 1970; 33: 439-44.

10 Chutorian AM, Schwartz JF, Evans RA, Carter S. Optic gliomas in children. Neurology 1964; 14: 83-95.

11 Walsh FB, Hoyt WF. Clinical neuro-ophthalmology. 3rd ed. Baltimore: Williams and Wilkins, 1969: 3: 1927-2331.

12 Yanof M, Fine BS. Ocular pathology: a text and atlas. New York: Harper and Row, 1975: Chapter 13: 482-513.

13 Hoyt WF, Baghdassarian SA. Optic glioma of childhood. $\mathrm{Br} \mathrm{J}$ Ophthalmol 1969; 53: 793-8.

14 Berke RN. A modified Krönlein operation. Arch Ophthalmol 1954; 51: 609-32.

15 Tym R. Piloid gliomas of the anterior optic pathways. Br J Surg 1961; 49: 322-31. 
16 Spencer WH. Primary neoplasm of the optic nerve and its sheaths: clinical features and current concepts of pathogenetic mechanisms. Trans Am Ophthalmol Soc 1972: 70: 490-528.

17 Marejeva TC, Rostotskaya JI, Sokolova ON, Vladimirova NA. Tumors of the optic nerve and chiasm in children. Acta NeurochirWien Suppl 1979; 28: 409-10.

18 Taveras JM, Mount LA, Wood EM. The value of radiation therapy in the management of glioma of optic nerves and chiasm. Radiology 1956; 66: 518-28.
19 Weiss L, Sagerman RH, King GA, Chung TC, Dubowy RL. Controversy in the management of optic nerve glioma. Cancer 1987; 59: 1000-4.

20 Rush J, Younge BR, Campbell RJ, MacCarty CS. Optic glioma. Longterm follow-up of 85 histopathologically verified cases. Ophthalmology 1982; 89: 1213-9.

Accepted for publication 10 May 1989. 